\title{
Assessment of perceived stress among resident trainees of a tertiary care hospital in Saudi Arabia during COVID- 19 pandemic - a cross-sectional study
}

\author{
Anwar ul Huda ${ }^{1}$, Mohammad Yasir ${ }^{1} \square$, Swaid Raza Saulat ${ }^{2} \square$, \\ Mohammad Waleed AlShaqha 3 \\ Authors affiliations: \\ 1- Consultant Anesthesiologist, Security Forces Hospital, Riyadh, Kingdom of Saudi Arabia. \\ 2- Registrar Emergency Medicine, Security Forces Hospital, Riyadh, Kingdom of Saudi Arabia. \\ 3- Resident Anesthesiology, Security Forces Hospital, Riyadh, Kingdom of Saudi Arabia.
}

Correspondence: Dr Anwar ul Huda, Consultant Anesthesiologist, Security Forces Hospital, Riyadh, Kingdom of Saudi Arabia; Email: hudaanwar90@yahoo.com

\section{Abstract}

Background \& Objective: The massive burden of COVID-19 disease is believed to be associated with significant psychological disturbances on healthcare professionals. Increasing levels of stress may lead to anxiety, depression, burnout syndrome, and in severe cases, post-traumatic stress disorder. The objective of this study was to examine the presence of stress among resident trainee doctors working in a tertiary care hospital in Saudi Arabia in the context of the corona pandemic.

Methodology: This was a cross-sectional study conducted in Security Forces Hospital, Riyadh, Saudi Arabia. We included the resident trainee doctors from different specialties of our hospital including medical, surgical, anesthesia, emergency room (ER), and critical care units. We used convenience sampling to select study respondents. Perceived Stress Scale (PSS) was used for assessing the stress levels among trainees. Trainees were requested to fill the questionnaire either online survey monkey or in paper form. All data were entered and analyzed using SPSS version 26. We calculated mean, standard deviation, frequency count, and percentages for the perceived stress.

Results: A total of 60 trainees were included in this study. Mean PSS-10 score was $20 \pm 5.51$, with a range between 6 and 34. Four (6.7 \%) trainees had low stress and 50 (83.3\%) trainees had moderate stress while 6 (10 \%) trainees had high stress

Conclusion: The majority of resident trainees in our study experienced a moderate level of anxiety during this COVID pandemic.

Key words: Stress, Resident trainees, COVID-19, pandemic

Citation: ul Huda A, Yasir M, Saulat SA, AlShaqha MW. Assessment of perceived stress among resident trainees of a tertiary care hospital in Saudi Arabia during COVID-19 pandemic - a cross-sectional study. Anaesth. pain intensive care 2021;25(2):185-188. DOI: 10.35975/apic.v25i2.1471

\section{Introduction}

In December 2019, few patients developed pneumonia of unknown origin in Wuhan (China) which was later named severe acute respiratory syndrome coronavirus 2 (SARS-CoV-2). ${ }^{1}$ WHO declared this disease a global pandemic on March 11, 2020. As of $13^{\text {th }}$ June 
2020, WHO reported a total of $52,177,708$ confirmed COVID-19 cases and 1,286,063 total deaths. ${ }^{2}$

The massive burden of COVID-19 disease is believed to be associated with significant psychological disturbances to healthcare professionals (HCP). Stress is defined as perceived discomfort which is stimulated by activities perceived as too intense and frequent and exceeds a person's coping capabilities and available resources to manage it. ${ }^{3}$ Increasing levels of stress may lead to anxiety, depression, burnout syndrome, and in severe cases, post-traumatic stress disorder (PTSD). ${ }^{4}$ Abdulghani et al. ${ }^{5}$ in their study showed that the overall stress level among resident trainees in Saudi Arabia was high (70.4\%), but the severe stress level among the resident trainees is lower than the medical undergraduate students and internship trainees. Some other reports also mentioned careers in medical specialties as stressful. ${ }^{6,7}$ Data about stress among resident trainee doctors during this COVID-19 pandemic is scarce and we could not find any study in Saudi Arabia.

\section{Research methodology}

This was a cross-sectional study conducted in Security Forces Hospital, Riyadh, Saudi Arabia. We included the resident trainee doctors from different specialties of our hospital including medical, surgical, anesthesia, ER, and critical care units. The sample size was calculated using the online calculator ${ }^{8}$ and came out to be 57 . We used convenience sampling to select study respondents. Ethical approval was taken from the institutional ethical review committee. The trainees were informed about the purpose and significance of this study. We used The Perceived Stress Scale (PSS) for assessing the stress levels among trainees. PSS is the most widely used psychological instrument for measuring the perception of stress. It is a measure of the degree to which situations in one's life are appraised as stressful. Items are designed to tap how unpredictable, uncontrollable, and overloaded respondents find their lives. Each item was answered by the trainees on a five-point scale ranging from never (0) to very often (4). ${ }^{9}$ The scale has been used in Saudi healthcare workers in one previous study by Alharbi et al. ${ }^{3}$

Trainees were requested to fill the questionnaire either through online SurveyMonkey (https://www.surveymonkey.com/) or in a printed paper form. All data were entered and analyzed using SPSS version 26. We calculated mean, standard

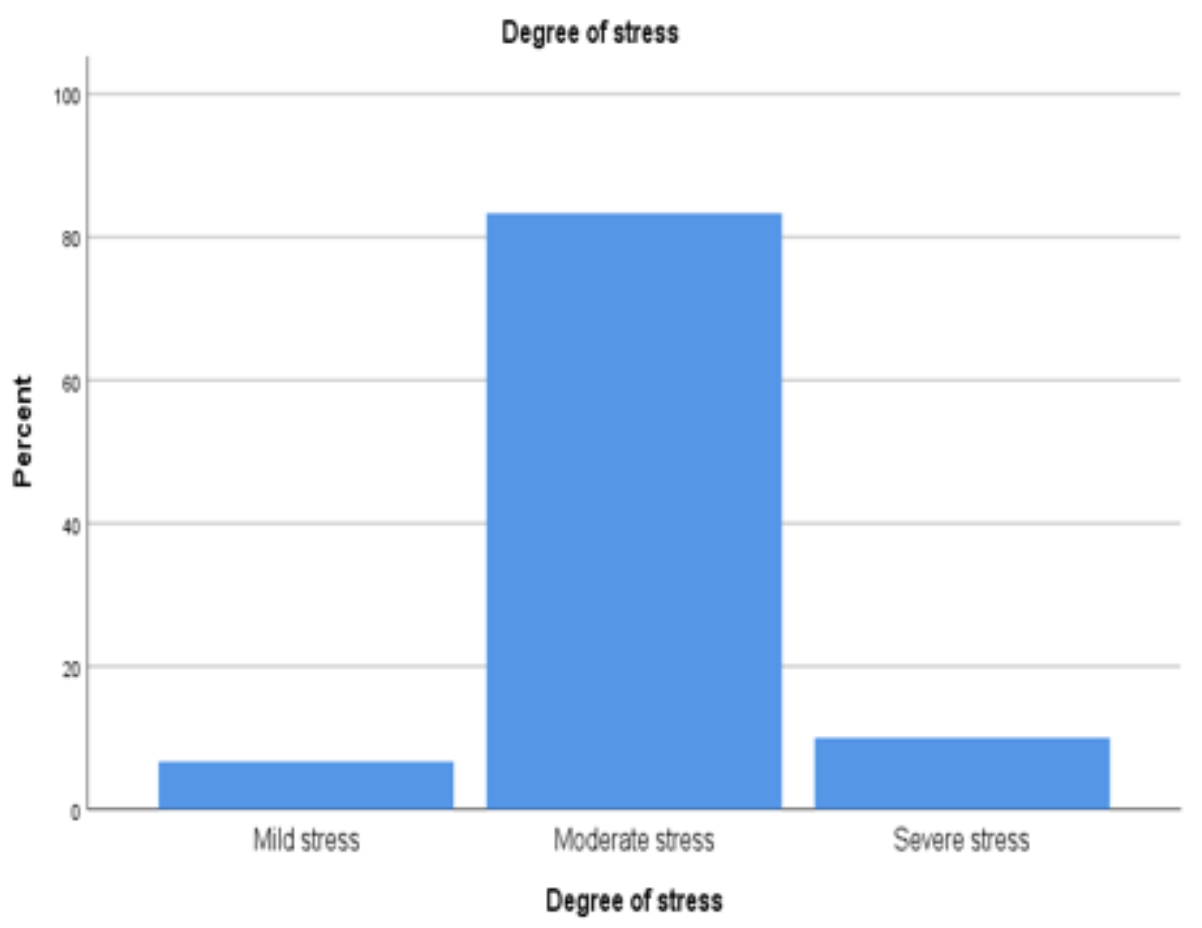

Figure 1: Degree of stress in trainees 
deviation, frequency count, and percentages for the perceived stress.

\section{Results}

A total of 60 trainees were included in this study. Fifteen $(25 \%)$ trainees filled the questionnaire using the SurveyMonkey link while 45 (75\%) filled the paper questionnaire. Mean PSS-10 score was $20 \pm$ 5.51 , with a range between 6 and 34. Four (6.7\%) trainees had low stress and $50(83.3 \%)$ trainees had moderate stress while $6(10 \%)$ trainees had high stress as shown in the Figure 1.

\section{Discussion}

Healthcare professionals are known to be more susceptible to psychological distress compared to other members of society. ${ }^{10}$ In one study in Jordan, poor psychosocial work environment, poor social support, and dealing with uncooperative patients were found to be associated with burn out among mental health nurses. ${ }^{10}$ Alharbi et al $^{3}$ showed that the mean score of PSS10 in ICU nurses of one of the government hospitals in Saudi Arabia was 17.71, which was lower than what we found in our study. Most of the nurses reported a moderate stress level while only a few experienced a low stress level.

With the current situation of COVID-19, this psychological aspect has got further worsened. Scientific literature from previous epidemics has shown significant individual and social psychosocial impact following epidemics and outbreaks in the past. ${ }^{11,12}$ During this COVID-19 pandemic, the world is going through a shutdown or slowdown in daily activities but on the other hand, HCPs need to continue their working schedules. ${ }^{13}$ Additionally, because of increasing healthcare demand, they have to work longer shifts, often with limited resources and with the need to wear personal protective equipment (PPE) resulting in physical discomfort as well. Also, they are at risk of getting infected and the risk of spreading the virus to their family and friends. This fear makes them to isolate themselves from family and friends, resulting in various levels of psychological pressures and dysphoric states like stress, irritability, fatigue, and despair. ${ }^{14}$

In 2003, during the outbreak of SARS (severe acute respiratory syndrome), 18-57\% of HCPs experienced serious emotional and psychiatric disturbances. During the outbreak of MERS (Middle East respiratory syndrome) in 2015, dysphoria and stress were reported among HCPs. ${ }^{15}$ During this COVID pandemic, a large survey of HCPs in $\mathrm{China}^{16}$ reported the prevalence rate of traumatic stress at $73.4 \%$, depression at $50.7 \%$, and generalized anxiety at $44.7 \%$, while our study demonstrated a very alarming percentage of moderate to severe stress (93\%) among resident trainees. These results were also much higher than reported by Abdulghani ${ }^{5}$ who reported overall stress level as 70.4 although the prevalence of severe stress level was much lower in our study at $10 \%$ compared to $22.6 \%$ reported by them.

\section{Conclusion}

The majority of trainee residents in our study experienced a moderate level of anxiety during this COVID pandemic. We, therefore, recommend that psychosocial support should be made available for trainee residents during the pandemic.

\section{Acknowledgements}

None

\section{Authors contribution}

AUH: Concept, literature search, Conduct of study, Data collection and entry, Data analysis, Manuscript writing and editing, Final approval

MY: Literature search, Conduct of study, Data collection, Manuscript editing, Final approval

SRS, MWA: Conduct of study, Data collection, Manuscript editing, Final approval

\section{Conflict of interests}

None declared by the authors. No funding was obtained to conduct this study from any source.

\section{References}

1. Li H, Liu SM, Yu XH, Tang SL, Tang CK. Coronavirus disease 2019 (COVID-19): current status and future perspectives. Int J Antimicrob Agents. 2020;55(5):105951. [PubMed] DOI: 10.1016/j.jijantimicag.2020.105951

2. World Health Organization. (2020, March 11). WHO characterizes COVID-19 as a pandemic. Available from: https://www.who.int/emergencies/diseases/novel-coronavirus2019/events-as-they-happen. 
3. Alharbi $\mathrm{H}$, Alshehry A. Perceived stress and coping strategies among ICU nurses in government tertiary hospitals in Saudi Arabia: a cross-sectional study. Ann Saudi Med. 2019;39(1):48-55. [PubMed] DOI: 10.5144/0256-4947.2019.48

4. Vahedian-Azimi A, Hajiesmaeili M, Kangasniemi M, Fornes-Vives J, Hunsucker RL, Rahimibashar F, et al. Effects of stress on critical care nurses: a national cross-sectional study. J Intensive Care Med. 2019;34(4):311-22. [PubMed] DOI: 10.1177/0885066617696853

5. Abdulghani HM, Al-Harbi MM, Irshad M. Stress and its association with working efficiency of junior doctors during three postgraduate residency training programs. Neuropsychiatr Dis Treat. 2015;11:3023-9. [PubMed] DOI: 10.2147/NDT.S92408

6. Lee J, Alferi M, Patel T, Lee L. Choosing family medicine residency programs: what factors infuence residents' decisions? Can Fam Physician. 2011;57(3):e113-21. [PubMed]

7. Hoonpongsimanont W, Murphy M, Kim CH, Nasir D, Compton S. Emergency medicine resident well-being: stress and satisfaction. Occup Med (Lond). 2014;64(1):45-8. [PubMed] DOI: $10.1093 /$ occmed/kqt139

8. Dhand N. K, Khatkar M. S. (2014). Statulator: An online statistical calculator. Sample Size Calculator for Estimating a Single Mean. Accessed 16 June 2020. Available from: http://statulator.com/SampleSize/ss1M.html

9. Cohen, S. and Williamson, G. Perceived Stress in a Probability Sample of the United States. Spacapan, S. and Oskamp, S. (eds.) The Social Psychology of Health. Newbury Park, CA: Sage, 1988.

10. Hamaideh SH. Burnout, social support, and job satisfaction among Jordanian mental health nurses. Issues Ment
11. Health Nurs. 2011;32(4):234-42. [PubMed] DOI: $10.3109 / 01612840.2010 .546494$

12. Li Z, Ge J, Yang M, Feng J, Qiao M, Jiang R, et al. Vicarious traumatization in the general public, members, and nonmembers of medical teams aiding in COVID-19 control. Brain Behav Immun. 2020;88:916-9. [PubMed] DOI: $\underline{10.1016 / j . b b i .2020 .03 .007}$

13. Ornell F, Schuch JB, Sordi AO, Kessler FHP. "Pandemic fear" and COVID-19: mental health burden and strategies. Braz J Psychiatry. 2020;42(3):232-5. [PubMed] DOI: 10.1590/1516-4446-2020-0008

14. Wilder-Smith A, Freedman DO. Isolation, quarantine, social distancing and community containment: pivotal role for oldstyle public health measures in the novel coronavirus (2019-nCoV) outbreak. J Travel Med. 2020;27(2):taaa020. [PubMed] DOI: $10.1093 /$ itm/taaa020

15. Huang JZ, Han MF, Luo TD, Ren AK, Zhou XP. [Mental health survey of medical staff in a tertiary infectious disease hospital for COVID-19]. Zhonghua Lao Dong Wei Sheng Zhi Ye Bing Za Zhi. 2020;38(3):192-5. [PubMed] DOI: $10.3760 / \mathrm{cma}$.j.cn121094-20200219-00063

16. Lee SM, Kang WS, Cho AR, Kim T, Park JK. Psychological impact of the 2015 MERS outbreak on hospital workers and quarantined hemodialysis patients. Compr Psychiatry. 2018;87:123-7. [PubMed] doi: 10.1016/j.comppsych.2018.10.003

17. Liu S, Yang L, Zhang C, Xiang YT, Liu Z, Hu S, et al. Online mental health services in China during the COVID-19 outbreak. Lancet Psychiatry. 2020;7(4):e17-e8. [PubMed] doi: $\underline{10.1016 / S 2215-0366(20) 30077-8}$ 